\title{
Trayectorias de género en la migración sur-sur de mujeres mexicanas calificadas en Santiago de Chile*
}

\section{Gender Trajectories in South-South Migration by Qualified Mexican Women to Santiago, Chile}

\author{
Nicolás Gissi Barbieri** \\ Universidad de Chile, Chile. \\ Susana Martínez Ruiz*** \\ Universidad de Chile, Chile.
}

Recibido: 16 de mayo de 2017. Aprobado: 18 de enero de 2018.

\begin{abstract}
Resumen
Con un enfoque de género, transnacional y cualitativo, el presente artículo se propone conocer los procesos de continuidad y transformación en los roles y estatus de género de mujeres mexicanas calificadas que actualmente residen en Santiago de Chile. Para ello, se realizaron seis historias de vida, poniendo en relieve las diferentes motivaciones migratorias (laborales, educativas y amorosas) y los perfiles de cambio o continuidad de los roles de género que tensionan las esferas de la producción y la reproducción en el contexto de la migración femenina. Finalmente, se problematiza acerca de las valoraciones otorgadas a la experiencia migratoria y cómo estas dan cuenta de la transformación hacia posiciones más autónomas, más

\footnotetext{
* El presente artículo es resultado de la investigación de Memoria "Desestabilizando las jerarquías. Roles y estatus en la migración de mujeres mexicanas calificadas en Santiago de Chile", realizada en el marco del proyecto FONDECYT N 11130287 "Migración y procesos de integración y exclusión social de colombianos y mexicanos en Chile. Estudio comparativo de dos casos de movilidad intralatinoamericana", programa al cual expresamos nuestros agradecimientos.

** Dr. en Antropología, Departamento de Antropología, Universidad de Chile. Código postal 7750000 , ngissi@uchile.cl Pinto 1045, Ñuñoa, Santiago, su.marruiz@gmail.com
}

**** Licenciada en Antropología Social y Antropóloga Social en Universidad de Chile, Av. Ignacio Carrera
\end{abstract}


emancipadas e independientes, promoviendo la migración como escenario propicio para desestabilizar la estructura tradicional de género.

Palabras clave: Migración Sur-Sur, transnacionalismo, mujeres mexicanas.

\begin{abstract}
This article uses a gender, transnational and qualitative approach to explore processes of continuity and transformation in the roles and gender status of qualified Mexican women currently residing in Santiago de Chile. Six life histories were developed, highlighting the various motivations for migration (work, education and love) and the profiles of change or continuity of gender roles that generate tension in the spheres of production and reproduction in the context of female migration. Finally, the author explores the value placed on the migratory experience and how it reveals the transformation towards more autonomous, emancipated and independent positions, identifying migration as a mechanism that contributes to the destabilization of the traditional gender structure.
\end{abstract}

Keywords: South-South migration, transnationalism, Mexican women.

\title{
Introducción
}

Hasta mediados de los años ochenta los estudios acerca de las migraciones internacionales mantenían una arraigada perspectiva androcéntrica (Ariza, 2000; Gregorio, 1998; Suárez, 2004). Las mujeres no sólo eran contempladas como acompañantes y aliadas del hombre migrante que buscaba mejores oportunidades laborales, sino que tampoco se consideraban los proyectos migratorios autónomos ni los roles que cumplían las mujeres participantes del fenómeno. En otras palabras, la migración era abordaba por medio de dos sesgos principales: considerarla eminentemente económica (productiva) y propiamente masculina (Gregorio, 1998). Estas tendencias provocaban una invisibilización de la mujer migrante dentro de 


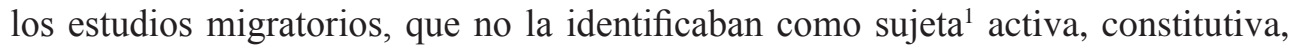
particular y transformadora de los clásicos intereses investigativos.

En términos contextuales, el actual proceso de feminización de la migración en algunas nacionalidades de Latinoamérica y el Caribe, la incorporación de la mujer al mercado del trabajo remunerado y la visibilización de su desempeño como jefas de hogar dentro de la economía familiar (contraponiéndose a la calificación de "ayuda" y a la de ingreso complementario, ampliamente difundida por estudios que resaltan los espacios productivo y reproductivo como ámbitos disociados), han puesto en relieve la importancia de las mujeres dentro de los flujos migratorios internacionales. Estas perspectivas, más allá de homogenizar la experiencia femenina en el contexto de las migraciones, lo que pretenden es identificar las diferentes y particulares motivaciones, consecuencias y trasformaciones que guían la decisión de migrar de las mujeres.

Para aproximarnos de manera adecuada, hemos incorporado la perspectiva de género como principio articulador y organizador de la movilidad humana, es decir, el género como categoría y perspectiva analítica de las migraciones. Ante esto, el género permite definir la migración internacional como un proceso generizado (Tapia, 2011) en un doble sentido, por un lado, como concepto explicativo que da sentido a la realidad, vivida de manera diferenciada por hombres y mujeres; y por otro, como concepto crítico que tiene la capacidad de desnaturalizar 'lo femenino' y 'lo masculino', junto con la inamovilidad de las mujeres a espacios fuertemente normativos (Tapia, 2011). Comprender esto, supone evidenciar que las migraciones femeninas están permeadas por diversos sistemas de desigualdades, como la raza, la clase, la ciudadanía y el género (Falquet, 2009), que tienen su correlato en aspectos tales como: el acceso a recursos económicos, las motivaciones para migrar, la integración en la sociedad de llegada, la generación de redes sociales y los proyectos de vida de las mujeres migrantes, entre otros.

De esta manera, analizar aspectos relativos a la división genérica/sexual del trabajo, la interacción de los espacios reproductivos y productivos, y las diferencias de género

La utilización del término sujeta/sujetas responde a la necesidad de incorporar un vocabulario específico que visibilice a la mujer como protagonista de esta investigación. 
que atribuyen características particulares a cada sexo/género es una tarea necesaria para descifrar la manera en que profundizan, transforman o mantienen el statu quo de las relaciones de desigualdad en el contexto migratorio.

Junto a lo anterior, el enfoque transnacional se constituye como un desafío importante, pues permite evidenciar la relación dialógica que existe entre las desigualdades estructurales de género y los proyectos migratorios individuales en el país de origen y el de destino, considerándolos como "dos espacios interconectados en los que toman prioridad las relaciones sociales e históricas de desigualdad y las influencias mutuas, tanto en las condiciones estructurales de ambas sociedades como en las subjetividades de las y los protagonistas de la acción social” (Gregorio, 1998, p. 11).

De esta manera, ambos contextos serán considerados como espacios donde se vinculan expectativas y razones subjetivas, así como también, donde se desarrollan, transforman, reestructuran y renegocian roles y estatus de género, que pueden influir fuertemente a la hora de iniciar, mantener o finalizar el proceso migratorio. Sin embargo, estos cambios no implican, necesariamente, la anulación de las desigualdades; si bien es posible destacar la migración como escenario que posibilita las transformaciones en las relaciones de género, no es posible establecer, de antemano, si dichos cambios reducirán o reforzarán las asimetrías (Gregorio, 1998).

Por otro lado, la especificidad de la experiencia migratoria de la población mexicana en Chile nos enfrenta a nuevos escenarios, que se relacionan directamente con los recientes patrones de movilidad latinoamericana: la migración calificada entre los países del Sur. Según Martínez (2017), la presencia de mexicanos y mexicanas en Chile se compone de tres características fundamentales: 1) se trata de una migración con altos grados de calificación; 2) se concentra, mayoritariamente, en sectores asociados a niveles socioeconómicos medios y medios-altos; y 3) contiene una importante presencia de mujeres en su desarrollo. Acorde a los intereses de esta investigación, trabajar con mujeres mexicanas calificadas es un objetivo explícito, pero que no está exento de dificultades. Dos ideas principales son las que permiten afirmar que la migración calificada en mujeres no ha sido un fenómeno estudiado con profundidad desde las ciencias sociales. La primera, es que, a pesar del creciente aumento de la migración Sur-Sur, existe un escaso interés a nivel investigativo por 
la migración calificada latinoamericana en general (Bermúdez, 2014), y la segunda, y particularmente referente a la perspectiva adoptada en esta investigación, es que el enfoque de género ha sido poco utilizado en el estudio de contextos migratorios calificados (Stang, 2006). Según Martínez (2008), algunas de las razones que podrían explicar este desinterés, estarían dadas por algunos supuestos erróneos como la lejanía de la mujer calificada con la situación de vulnerabilidad en el proceso migratorio en comparación a otras no calificadas, la escasa disponibilidad de información desagregada por sexo, y que las mujeres son minoría entre la fuerza de trabajo calificada, los talentos y los profesionales.

Es por lo anteriormente señalado que este articulo tiene como propósito dar a conocer las trayectorias de género asociadas a la migración de mujeres mexicanas calificadas hacia Santiago, identificando las transformaciones y/o continuidades en sus roles de género dentro de los contextos de origen y destino.

\section{Desarrollo}

\section{Las trayectorias migratorias desde una perspectiva de género}

La migración internacional, entendida como un hecho social total (Mauss, 1924; Sayad, 2010) que "no sólo impacta en las estructuras económicas, sociales y políticas a nivel global y local, sino que también debe afectar a las vidas de quienes la acometen" (Gregorio, 2012, p. 580), ha sido abundantemente estudiada desde la perspectiva de las trayectorias migratorias. La salida del país de origen suele devenir en un hito biográfico en los y las emigrantes, en cuyos procesos de inserción y des/ arraigo se viven experiencias de contacto personal y cultural con la sociedad de recepción, implicando distintas emociones, alegrías y dolores, reconocimientos y discriminaciones, las que propician tanto transformaciones como continuidades en los roles de género. Siguiendo a García-Moreno y Pujadas (2011), las trayectorias migratorias corresponden a una realidad procesual compuesta por el proyecto migratorio y por las estrategias migratorias que se activan para su realización. Mientras el primero se relaciona con la orientación general, planes y expectativas de futuro que están presentes en cada momento de la trayectoria, las segundas 
dan cuenta del cómo se emigra y qué se pone en marcha para emigrar/inmigrar. Bermúdez (2014) considera que el estudio de las trayectorias permite tener una perspectiva a largo plazo y una visión dinámica del comportamiento de las sujetas en ámbitos específicos o interrelacionados, incluyendo la identificación de transiciones o puntos de inflexión (turning point)], que permiten dar cuenta del carácter procesual de las trayectorias. Si nos situamos en el estudio de las trayectorias migratorias desde una perspectiva de género, este punto adquiere especial relevancia debido a que permite la reconstrucción de las experiencias de mujeres y el entrelazamiento de aspectos relativos a la maternidad, el trabajo asalariado, el trabajo doméstico o de "reproducción", los niveles de escolaridad, la clase social y las relaciones intergenéricas, entre otros (García y Oliveira, 1998; Pacheco y Blanco, 2008).

Para poder analizar las trayectorias migratorias desde una perspectiva de género, debemos precisar que hemos utilizado la noción de que lo productivo y lo reproductivo se constituyen como un sistema social cohesionado. Considerando las dialécticas trabajo reproductivo/trabajo productivo $^{2}$, mujer/hombre, privado/público la diferencia radica, fundamentalmente, en el valor social y económico atribuido a cada caso: mientras a la mujer se le asignan todas aquellas tareas relacionadas con la reproducción (cuidados del hogar, maternidad, crianza y el cuidado de los otros) a los hombres se les identifica con el trabajo asalariado, lo productivo y lo público (Lamas, 2003). De esta manera, lo reproductivo es advertido como carente de ambos valores mencionados y por consecuencia, invisibilizado a nivel social, político y académico (Benería, 2006; Celiberti y Mesa, 2009). A pesar de esto, los esfuerzos del feminismo marxista y económico por visibilizar y relevar la importancia del trabajo reproductivo y la desigualdad existente en la división genérica/sexual del trabajo (Benería, 2006; Gregorio, 1998; Mazzei, 2013; Valerdi y Garabito, 2013; Valerdi, 2011) han tenido sus frutos, promoviendo la visión de que si bien explicativamente, es posible entender de manera separada lo reproductivo de lo productivo, no es sino comprendiéndolos como parte de un solo sistema que se destaca la importancia

2 Los trabajos de Gorz (1995) y Carrasco (2001) plantean que la limitada noción de trabajo impulsada con el capitalismo industrial, que comprende el trabajo como el que ocurre sólo dentro del mercado, provoca que las actividades sin remuneración desarrolladas por los miembros del hogar, es decir, las reproductivas, sean invisibilizadas y concebidas como no trabajo. A partir de lo anterior, suele identificarse, casi exclusivamente, el trabajo con el empleo, es decir, el que ocurre en el espacio público y tiene un correlato salarial "de producción". 
de la economía del cuidado para el funcionamiento de la sociedad (Benería, 2006; Federici, 2013; Folbre, 1994). Así, nos proponemos evidenciar la separación artificial entre los espacios reproductivos y productivos, pues “(...) siempre que exista una acción en cualquiera de esos polos, habrá repercusión de uno sobre el otro, dada la articulación viva que existe entre las esferas del trabajo y de la reproducción" (Mazzei, 2013, p. 129).

\section{Roles y estatus de género como performance}

Considerando los planteamientos de Simone de Beauvoir y su clásico "No se nace mujer: se llega a serlo" (1969, p. 109), Butler (1990) posiciona al género como una identidad dinámica, débilmente constituida en el tiempo e institucionalizada por medio de la repetición ritualizada de actos, es decir, el género como performance. Comprendido como un modelo de temporalidad social más que como uno de identidad sustancial, el género, y con ello roles y estatus asociados, son el resultado performativo de la acción de los individuos, acción que se constituye como materialización de posibilidades, construcción/situación y estrategia de 'sobrevivencia' coaccionadas y sancionadas por la historia y la sociedad. Al mismo tiempo en que los individuos realizan la repetición ritualizada de los actos, van creando, enunciando, dramatizando, resistiendo y reproduciendo la situación histórica que es el género.

El género no está pasivamente inscrito sobre el cuerpo y tampoco está determinado por la naturaleza, el lenguaje, lo simbólico o la historia del patriarcado. El género es lo que uno asume, invariablemente, bajo coacción, a diario e incesantemente; con ansiedad y placer, en donde se puede tener el poder de ampliar el campo cultural corporal con performances subversivas de distintas clases (Butler, 1990, p. 314).

Así, los roles y estatus asociados de forma naturalizada a las diferentes expresiones de género se constituyen como construcciones sociales, culturales e históricas posibles de ser transformadas y que interactúan en un entramado dinámico de relaciones sociales. La teoría de Butler (1990) pone en relieve entonces la capacidad transformadora de los y las agentes sociales, donde lo que ha sido construido en un 
contexto cultural, social e histórico dado, puede reconstruirse para volver a ser de nuevo construido (Duque, 2010).

A partir de lo anterior, consideraremos los roles de género como los 'papeles', tareas y responsabilidades que se han constituido a partir de la acción diferenciada de hombres y mujeres, configurados en torno a las acciones, normas y expectativas que propone la sociedad y la cultura sobre el comportamiento femenino y masculino. Al respecto, Lamas (2003) señala que:

El papel (rol) de género se configura con el conjunto de normas y prescripciones que dictan la sociedad y la cultura sobre el comportamiento femenino o masculino (...) pero hay que tener en cuenta que, si el género es una distinción significativa en gran cantidad de situaciones, es porque se trata de un hecho social, no biológico (p. 114).

Por su parte, el estatus de género referirá “(...) al valor y el significado que la sociedad otorga a hombres y mujeres dependiendo del desempeño de sus roles" (Gregorio, 1998, p. 85). Para efectos de este texto, el estatus será identificado en relación a las valoraciones y significaciones que las propias mujeres hacen de sus roles en el contexto migratorio, así como el valor y las significaciones que su contexto familiar realiza acerca de la migración femenina y el desempeño de sus roles.

\section{Algunas consideraciones sobre la migración mexicana en Chile}

La migración de población mexicana hacia Chile puede situarse dentro del contexto de la migración intra-regional Sur-Sur, que según la OIM (2014), involucra todos los flujos y desplazamientos de personas entre países en vías de desarrollo, dentro del territorio de América Latina y el Caribe. La migración intra-regional posee sus orígenes en la heterogeneidad económica y social de sus países. Tanto los factores político-sociales (contextos de inestabilidad política, aumento de las restricciones a la inmigración en los países del Norte) como los factores económicos (crecimiento sostenido de la economía, reducción en los niveles de pobreza y desigualdad, mayor diversificación del mercado de trabajo) han incidido de manera importante en los 
patrones migratorios de los países latinoamericanos y del Caribe, que se orientan cada vez más hacia flujos intra-regionales (Garcés, 2015; Polloni y Matus, 2011; Stefoni, 2001; Texidó y Gurrieri, 2012). El aumento de las corrientes migratorias entre los países de América Latina y del Caribe se ha presentado en conjunto a tres procesos importantes: la feminización de la migración, la circularidad de los flujos y el crecimiento de la población calificada (Lozano y Gandini, 2011; Martínez, 2003; Mora, 2009).

Dentro de este mismo contexto, las recientes características de la migración en Chile concuerdan con los patrones generales de la región, refiriendo a un notorio aumento, sobre todo en las últimas décadas, de la inmigración latinoamericana y del Caribe, al mismo tiempo que una disminución en la inmigración desde países europeos y el resto del mundo. A lo anterior se suman otras características, como el predominio de mujeres, quienes representan el 51,9\% del total de la población migrante (CASEN, 2015), mayores niveles de educación y la concentración en edades de población económicamente activa (Solimano y Tokman, 2008).

La migración mexicana en Chile es un fenómeno poco documentado a nivel nacional, lo que puede deberse a dos factores principales: se trata de una migración nueva y no posee una gran representatividad cuantitativa dentro del territorio ni de la población nacional total. Partiendo de esta afirmación es que presentamos algunas características demográficas de la población obtenidas a partir de las cifras otorgadas por el Departamento de Extranjería y Migraciones (DEM, 2015) y la sistematización de dichos datos realizada en la investigación "Desestabilizando las jerarquías. Roles y estatus en la migración de mujeres mexicanas calificadas en Santiago de Chile" (Martínez, 2017). Si bien los datos obtenidos desde el organismo público corresponden a la documentación oficial de visas y residencias otorgadas a mexicanos y mexicanas en Chile durante el período 2005-2014, sólo deben considerarse como estimaciones referenciales debido a que las bases de datos del DEM no están construidas para fines estadísticos (Martínez, 2011) y son limitadas en cuanto a alcance y representatividad. De esta forma, no es posible determinar con precisión las características sociodemográficas de la población mexicana residente en Chile, aunque sí tendencias generales. 
Durante el período de 2005-2014, el DEM entregó 10.009 visas (temporarias, definitivas, sujetas a contrato y de estudiantes) a mexicanos y mexicanas en nuestro país. Las cifras han aumentado de manera progresiva, pues si el año 2005 se otorgaron 598 permisos, para el año 2014 fueron 1460, creciendo en un 140\%. Es de destacar que la cantidad de visas y permisos de residencia no deben ser homologadas a toda la población mexicana residente en Chile, debido a que la información disponible no sustrae la cantidad de casos que tienen más de un beneficio o la población que ya no se encuentra en el país. A pesar de esto, se utilizó este dato como referencia para la estimación de patrones sociodemográficos como edad, sexo, nivel de estudio, regiones y comunas de residencia.

Con respecto al sexo, se aprecia que las mujeres representan un $48,5 \%$, mientras que los hombres representan un 51,5\% del total de la población mexicana en Chile. Si bien no existen fundamentos suficientes para referirnos a una feminización de la migración mexicana en Chile en términos cuantitativos, el proceso de feminización nos enfrenta a diversos escenarios que permiten visibilizarla más allá del componente numérico: emerge como herramienta eficaz para analizarla, en cuanto permite problematizar, en términos cualitativos, los diferentes significados que tiene el proceso migratorio para las mujeres, con las características particulares de su condición de género (diferente a la masculina).

En relación a la edad tanto de hombres como de mujeres, se evidencia que el $90 \%$ de la población mexicana que migra hacia Chile se concentra entre los 15 y los 59 años, es decir, se trata de una población joven y que se incluye dentro de la población económicamente activa según la clasificación del INE (2010). No aparece en las referencias respecto a la calificación, poseen niveles de estudio concentrados en el universitario $(54,4 \%)$, medio $(23,3 \%)$ y técnico $(11,4 \%)$. Agrupando los niveles de educación de tipo terciario, es decir, técnico y universitario, estimamos que un $65,8 \%$ de las personas que contestaron su nivel educativo pertenecen al segmento de población calificada.

La mayoría de la población mexicana reside en la Región Metropolitana, siendo las comunas donde más se concentran Las Condes (26,6\%), Santiago $(16,8 \%)$ y Providencia $(13,4 \%)$, asociadas a altos niveles de calidad de vida. 


\section{Aproximaciones metodológicas para la producción de datos de campo}

La información aportada sobre las trayectorias de género se construyó a partir del enfoque cualitativo, y dentro de las técnicas acordes a esta perspectiva, hemos utilizado las historias de vida de seis mujeres mexicanas inmigrantes en Santiago, acercándonos a las significaciones que ellas mismas le dan a su experiencia migratoria, además de comprender la forma en la que ellas (re)construyen sus historias individuales, familiares y el contexto situacional del acá y del allá (Cea y Valles, 2010).

Los criterios muestrales responden a intereses cualitativos, no probabilísticos y que no pretenden ser representativos de la experiencia mexicana en su totalidad. Estos fueron definidos a partir de un eje temporal, que contemplara lo reciente de la migración mexicana dentro del territorio nacional y un tiempo de estadía mínimo que permitiera observar cambios o continuidades en relación a los roles y estatus de género vividos en México; un eje estructural, que tome en cuenta la posición social en relación a la formación académica; $y$, finalmente, un eje geográfico que permita agrupar a las entrevistadas en torno a las comunas de Santiago con mayores porcentajes de inmigrantes mexicanos/as a nivel regional. Así, trabajamos con mujeres de nacionalidad mexicana, económicamente activas ${ }^{3}$ y calificadas, que residen en Santiago de Chile hace al menos dos años y que al momento de ser entrevistadas estuvieran viviendo en las comunas de Santiago, Providencia o Las Condes.

En esta dirección, abordamos las características del contexto de origen junto a las motivaciones, redes migratorias e información sobre el país de destino, además de las relaciones de género en la unidad doméstica de origen y destino, los significados atribuidos a la migración, al trabajo asalariado, la maternidad y crianza, el matrimonio, la división genérica/sexual del trabajo y las relaciones de pareja. Las entrevistas fueron realizadas al alero de aspectos éticos como la confidencialidad y el anonimato, explicitados escrita y verbalmente a las participantes por medio de la

Según el INE (2010) la población económicamente activa o fuerza de trabajo, refiere a toda aquella persona residente en edad de trabajar (15 años o más) y que se encuentre en la situación de ocupada o desocupada. 
utilización de consentimiento informado.

Dentro de este abordaje, tuvimos en cuenta que las características que se infieren de la calificación están referidas al hecho de que todas las mujeres participantes de esta investigación comparten, además de las condiciones materiales que le permiten el acceso al campo educativo de nivel terciario, un habitus, en términos de Bourdieu (2007), marcado por las huellas de este campo. Esto permite suponer, aunque de diversas maneras, que su posición en la estructura social -de origen y destino- está estrechamente relacionada a dichos elementos, presentando la calificación como una cualidad que otorga una forma específica de proyectar y desarrollar la experiencia migratoria (Stang, 2006). Así, consideramos como migrante calificada a toda mujer que haya emigrado de su país de origen con estudios de nivel terciario finalizados, ya sean técnicos y/o universitarios.

Para el análisis de los datos, nos servimos del análisis de discurso y las lógicas propuestas por Cornejo, Mendoza y Rojas (2008) quienes plantean, en primer lugar, una lógica intracaso o de la singularidad donde se reconstruyeron las historias identificando y articulando los principales hitos biográficos. En segundo lugar, la lógica intercaso o transversal, en la que se identificaron las categorías temáticasanalíticas relevantes para los objetivos de investigación, se generaron reflexiones generales e hipótesis comprensivas transversales. En la tercera etapa, se realizó la construcción del texto de análisis, donde se revisó la pertinencia de los ejes temáticos, se articularon las diferencias y similitudes de cada caso y se vincularon los datos obtenidos con los supuestos teóricos.

\section{Las trayectorias de género en la migración de mexicanas calificadas hacia Santiago de Chile}

Los relatos de vida que aquí abordamos ${ }^{4}$ provienen de mujeres mexicanas calificadas que tienen en común cinco características en relación a su contexto de origen: a partir de un criterio de autoidentificación subjetiva, las entrevistadas se sitúan dentro

4 Los resultados son ejemplificados a través de citas textuales correspondientes a cada una de las entrevistadas, para lo cual se han utilizado nombres ficticios. 
de las clases medias mexicanas, considerando su heterogeneidad (especialmente en México, país que se ha destacado históricamente por la existencia de educación superior gratuita), destacando la educación formal como un valor central de vida, correlato de sus aspiraciones por conservar o aumentar el lugar que se hereda en la estructura social; tienen un marcado origen urbano; provienen de familias patriarcales, donde la división sexual/genérica del trabajo se realiza en base al modelo tradicional (mujeres de la casa, hombres del trabajo); eran económicamente activas, estaban empleadas y se desenvolvían en áreas relacionadas, directa o indirectamente, con sus áreas de formación; y, finalmente, se constituyen como la primera generación de migrantes internacionales dentro del núcleo familiar, configurándose Chile como el país de destino donde han podido establecerse de manera más prolongada dentro de su trayectoria migratoria.

Haciendo énfasis en los procesos que dan inicio a su trayectoria migratoria hacia Chile, fue posible distinguir tres tipos de motivos. Las motivaciones de tipo educativas, están relacionadas con la continuación de la trayectoria educativa en pos de una carrera profesional ascendente (Salt, 1984). Para aquellas mujeres que migraron por esta razón, estudiar sólo la licenciatura y no obtener otros grados de calificación implica un desajuste con el mercado laboral futuro, ya sea en nuevos contextos de residencia o en el contexto de un eventual retorno. Este desajuste es representado como una "falta de herramientas" para el desarrollo de sus proyectos profesionales y el enfrentamiento con otros agentes dentro del campo laboral y académico.

(...) quería estudiar una maestría de todas maneras, o sea, no quería quedarme sólo con la licenciatura, creía que me faltaban herramientas (...) yo me di cuenta terminando mi carrera que tenía que hacer algo más para poder sobresalir, yo necesitaba herramientas para cuando regresara enfrentarme a ese gran mundo y poder hacer las cosas bien (Ana, 29 años).

La mayoría de mis compañeros de universidad, que eran mi referente, se habían ido a España, a EEUU, a Australia también y a mí como me interesa el sector público, la gestión pública, buscaba, y buscaba y decía, actuando de una manera muy inteligente, si yo me voy a un país europeo a estudiar gestión pública, o políticas públicas, sí tiene mucho valor, pero al momento 
de la implementación en un país subdesarrollado no tiene tanto, porque las realidades son distintas, no es lo mismo, claramente, Suecia que México. El desarrollo es totalmente distinto a cualquier país de Europa. Entonces era como ser más de lo mismo... (Carolina, 30 años).

(...) decidí especializarme en la dirección y me puse a buscar, "San Google" (risas). Y me puse a buscar dirección escénica y ahí me di cuenta que la Universidad de Chile es la única universidad que tiene esa mención en toda Latinoamérica y me sale, magister en artes con mención en dirección teatral y me puse a mirar la malla curricular y a ver el contenido y quedé, así como impactada, emocionada y decía ¿Chile? No sabía nada de Chile. O sea, sabía cómo era el país geográficamente, entendía eso, tenía un poco de contacto sobre la dictadura, pero nada más. Así como que dije, ¿Chile? ya po, será (Ana, 29 años).

Sus discursos van organizando cuatro factores claves para comprender el inicio de la emigración: (1) la representación de Chile como destino poco común para la realización de estudios de posgrado; (2) el conocimiento del país receptor, por lo general, vinculado a sus áreas de formación; (3) la obtención de becas académicas como facilitadoras tanto para el inicio como la mantención de la migración hacia el territorio nacional, y (4) la falta de disponibilidad o descontextualización de programas de formación especializados en sus áreas de formación en origen.

Las motivaciones de tipo laboral están inspiradas en la búsqueda de mejores oportunidades o en el ascenso en las estructuras de poder dentro de empresas transnacionales. Para aquellas que venían con una oferta de trabajo previamente concertada, la migración se lleva a cabo en contextos de estabilidad, que permiten planificar el acceso a recursos al mismo tiempo que externalizan la decisión migratoria, pues es tomada más en relación a los intereses empresariales que a una convicción propia.

Regresé de Francia cuando terminé mi posgrado, la idea para mí era quedarme en México, en mi mente no estaba irme a ningún otro país, y en realidad el país que pensaba si algún día tenía que volver a salir de 
México era Alemania, ni siquiera Francia. Chile no pasaba por mi cabeza por ninguna razón, por ignorancia, desconocimiento, por lo que tú quieras, Chile no estabas dentro de mis prioridades para migrar (Lorena, 44 años).

Para aquellas que llegaron sin contrato, la migración es significada como una aventura dentro de un contexto de incertidumbre, sobre todo en los primeros meses de su estadía. Para estas últimas, la elección de Chile como país de destino emerge de manera planificada, sin embargo, no pasa por razones de exclusiva índole económica, ya que "difícilmente el mexicano promedio piensa en venir a trabajar aquí" (Sofía, 28 años).

A pesar de las diferencias, la salida de México se hace necesaria en cuanto permite un avance cualitativo en su desarrollo profesional. Seguir trabajando allá implicaba un estancamiento y una limitación para obtener cargos de mayor prestigio.

Yo estaba trabajando ya oficialmente en la universidad donde estudié, tenía un cargo administrativo, la verdad yo ganaba muy bien para ser mujer soltera a mi edad, yo tenía 25 años, vivía muy bien, pero yo profesionalmente, en el puesto en que yo estaba, ya no iba a pasar de ahí, entonces no había crecimiento... mi jefe era el vicerrector, y jamás tendría el puesto de vicerrectoría (Sofía, 28 años).

Por su parte, las motivaciones amorosas se caracterizan por el afán de acompañar a parejas de nacionalidad chilena con la finalidad de formar una familia. A diferencia de las migraciones educativas y laborales, el proyecto migratorio por vínculo amoroso responde a intereses colectivos, sin embargo, este aparente carácter colectivo suele acoplarse a las aspiraciones económicas/laborales o familiares de sus respectivas parejas. Así, la construcción del discurso y la descripción de su proyecto migratorio, es realizado desde la centralidad otorgada a los sentimientos y el amor, y no tanto desde las oportunidades económicas o laborales individuales que podrían configurarse dentro de la aventura hacia Chile. Más allá de la importancia otorgada a las emociones y debido a que se trata de mujeres calificadas, es posible advertir un balance entre el sentimiento amoroso y otros factores como los intereses personales, las posibilidades laborales de cada uno/a, redes familiares así como los contextos 
sociopolíticos de los países, en que destaca Chile como seguro y estable política y económicamente, en contraposición con México, el cual se suele describir con alta inseguridad, violencia, corrupción y nepotismo, especialmente en algunos estados del área central y norte de México, sin embargo, el destino termina siendo un destino masculino (Stang, 2006).

En todas las mujeres que migraron por motivos amorosos emerge una idea sacrificial de la migración, pues si bien representa el comienzo de una aventura amorosa la decisión de emigrar implicó una serie de renuncias personales en el plano laboral, en la formación profesional y con el núcleo familiar en origen.

Él renunció a su trabajo y yo renuncié a mi vida y me vine a vivir a Chile, esa es la verdad, porque cuando me vine a vivir a Chile, en México yo me había comprado una casa propia, tenía un auto propio, tenía un trabajo y tenía lo más importante, que tenía a mi familia, a mis padres y a mi entorno y a mis amigos, y entonces todo eso quedo atrás (Fernanda, 44 años).

Satisfactorio en el aspecto del matrimonio. O sea, yo mi vida aquí es Cristian, o sea, si él se muere yo no sé qué voy a hacer, porque yo deje todo por él, todo, todo, todo. O sea, hablo con mi mamá por Skype a diario, pero lo deje todo, me costó muchísimo trabajo adaptarme, o sea, ahorita te podría decir que disfruto mi estancia aquí, pero al principio los primeros dos años fueron terribles, o sea, el shock cultural (Matilde, 34 años).

El dispositivo de género que opera sobre la construcción social de la maternidad y el matrimonio tiene profundos efectos tanto en la forma en la que se construye el discurso en torno a la migración amorosa como en la misma decisión para emprender el viaje. Para Stang (2006), ambas situaciones tienen un efecto inhibidor ante las decisiones que priorizan intereses exclusivamente laborales o educativos.

En el mismo camino, la migración amorosa viene asociada de manera ineludible a la idea de matrimonio y co-residencialidad con la pareja en el lugar de destino. El matrimonio es concebido como un requisito para la visualización exitosa de la experiencia migratoria, además de ser un factor 'facilitador' en términos de mayores 
niveles de estabilidad económica, proyecciones a largo plazo y la obtención expedita de visas.

Entonces yo le dije, sabes que, yo voy a dejar todo, voy a renunciar a mi trabajo, a mi familia, a mis amigos, a mi país y todo y a mí no me vas a hacer la que vivimos juntos así no más y si no funciona chao. Si tú en seis meses no me propones algo serio, yo me regreso. Bueno pues el 14 de febrero yo tenía un anillo en mi mano (risas) (Matilde, 34 años).

Pero cuando yo llegué aquí, me casé aquí, porque mi suegra decía que teníamos que estar casados por el tema de la salud y los papeles, era en el fondo como un trámite y lo hicimos (Fernanda, 44 años).

Es interesante distinguir las diferencias respecto a la activación, contingente o planificada, de redes familiares, institucionales, de amistad y/o de paisanaje, pues mientras la articulación de redes migratorias previas a la migración (sobre todo las de tipo institucional) estuvo más presente en el discurso de las mujeres motivadas por lo laboral y educativo, para las mujeres que migraron por amor suelen tener más relevancia las redes realizadas en destino y las asociadas a su pareja y situación conyugal. Para estas últimas, los proyectos migratorios suelen estar asociados a un tipo de incorporación directa y dependiente (Bodoque y Soronellas, 2010). Directa, en el sentido de la ausencia de redes de apoyo propias para la migración y la supuesta garantía, al menos en principio, que puede significar la relación conyugal en la inserción familiar y el acceso a la vivienda y otros recursos básicos. Sin embargo, es dependiente pues tanto la construcción de redes y la incorporación en la sociedad de acogida se encuentra capitalizada por el compañero sentimental, dependiendo de él y su entorno social.

\section{Perfiles de cambio y continuidad en torno a los roles de género}

A partir de los relatos de vida, nos fue posible evidenciar la relación directa que existe entre el desempeño de los roles de género y las motivaciones para migrar, siendo estas últimas las que marcan diferencias en la direccionalidad e intencionalidad en 
los proyectos de movilidad, interactuando con otras variables como la maternidad y el tipo de relación conyugal. A partir de ahí, fue posible identificar tres perfiles principales, los cuales surgen a partir de la intersección entre las esferas de la producción y la reproducción tomando como eje la migración. Es preciso mencionar que estos perfiles intentan definir una realidad dinámica y compleja, y que lejos de ser estados inmutables, corresponden más bien a un esfuerzo por problematizar la migración femenina calificada articulando los espacios de la reproducción y la producción.

Dentro del primer perfil, el de la intensificación de los roles productivos, se sitúan aquellas mujeres solteras, sin hijos, que han migrado para acceder a mayores grados de calificación y/o mejores oportunidades de trabajo y que, al momento de ser entrevistadas, se encontraban empleadas. En sus discursos, la migración emerge como ciclo y transición hacia la concreción de proyectos de desarrollo personal, laboral y educativo más que hacia el cumplimiento de roles de esposa o madre, dando especial importancia al trabajo asalariado: les permite acumular capital económico, desarrollarse profesionalmente y participar en el espacio público, además de generar remesas para la mantención o parte de la mantención de sus familias en origen.

Mentalmente mi ciclo lo divido en tres. Inicio, medio y fin. Entonces mi inicio fue el magister, dos años, entonces yo dije no, me hace falta la parte de aplicar lo que yo aprendí y de desarrollarme profesionalmente, entonces estoy como en la mitad de mi ciclo, estoy como en dos tercios del ciclo completo. Obviamente mi último tercio sería una estabilidad económica mucho más fuerte, no sé, tal vez adquirir algún bien inmueble. Yo creo que me sentiría mucho más concreta y más satisfecha en todos esos ámbitos (Carolina, 30 años).

Dependiendo del ciclo de vida en que las mujeres se sitúen, la maternidad no aparece proyectada o bien emerge como una posibilidad a largo plazo, que se posterga en tanto dificulta o limita la completa atención a la formación académica y el ascenso hacia mejores puestos de trabajo. A pesar de esto, se posicionan desde nuevos 
territorios para ejercer nuevas maternidades de tipo no hegemónicas. ${ }^{5}$

No me apura, no me preocupa porque yo estoy clara en eso, pero también tengo claro que la sociedad no lo ve así. Sí, voy a hacer madre, esa es una realidad. Ojalá pueda tener una familia, pero tampoco descarto la posibilidad de ser madre soltera o de adoptar o de cualquier forma que tenga de ser madre, lo voy a hacer (Ana, 29 años).

Mis hermanas siempre que juegan con las muñecas y que se querían casar y tener hijos y todo la historia de siempre de las niñas, y para mí nunca fue eso o sea yo decía, que no, no daba la espalda a eso tampoco porque es la naturaleza humana también, entonces yo siempre he dicho hasta hoy, nunca ha sido un tema para mí el matrimonio, por ejemplo, el hecho de tener hijos en algún momento lo pensé y dije sí, me gustaría tener un hijo pero si no es en cierta edad, en un rango de edad mía por supuesto, ya no lo voy a tener, y pasó ese rango de edad, digamos que para mí nunca fue algo que tenía que hacer (Lorena, 44 años).

Las relaciones de pareja cumplen un rol importante dentro de sus vidas, sin embargo, éstas son miradas con distancia debido a la dificultad que, según ellas, interviene en el encuentro de parejas que sean capaces de comprender sus obligaciones, intereses y responsabilidades en cuanto al desempeño de sus roles productivos.

Entonces por mucho que puedan decir, es difícil encontrar a una pareja que entienda, porque yo tengo que viajar, tengo que salir a comer con no sé quién, a cenar, y después la otra semana otra vez. Entonces no es tan fácil para una pareja entender esa situación. Una mujer tiene que entender

5 Para esta investigación, hemos definido maternidades no hegemónicas como todas aquellas maternidades que quedan fuera de las maternidades tradicionales y que no cumplen con mandatos como la heterosexualidad, heteronormatividad, relación de pareja y estado de fertilidad. Así, la idea de nuevas maternidades no hegemónicas queda enraizada en dos aspectos fundamentales, serán madres fuera de la norma aquellas mujeres que realizan actividades de cuidado y educación de sus hijos/as, sin tener una necesaria relación biológica, que no la establecen dentro de una relación de pareja y que han acudido o piensan acudir al mercado reproductivo, es decir, adopción, acogimiento, fertilización asistida con o sin donante, autofecundación, entre otras. Para un desarrollo más profundo de este concepto, sugerimos revisar la investigación de Burgaleta (2011). 
esa situación al hombre, pero el hombre no es tan fácil que entienda lo contrario. Podrán decir lo que quieran, pero los hombres no asumen el rol de una mujer en ninguno de los ámbitos entonces es muy difícil (Lorena, 44 años).

A pesar de que las mujeres que integran este perfil han orientado sus roles de género hacia unos que, de un modo u otro, escapan de la estructura patriarcal, han experimentado el peso de lo normativo a través de los procesos de masculinización en el ámbito laboral. Ya sea por el carácter de sus cargos y/o la competencia laboral con hombres dentro de su misma área de formación, estos procesos han traído serias consecuencias que van desde el acoso laboral y la deslegitimación de sus capacidades, hasta la desvalorización salarial y una sobrecarga de trabajo, traducida en un esfuerzo adicional por mantener su posición dentro de la jerarquía de cargos, siempre masculina.

Yo les digo no señores, perdónenme porque aquí mi salario no es el que le darían a un hombre, mi salario es menor, y después la verdad es que cuesta, aquí en particular en Chile cuesta mucho trabajo integrarse dentro del ambiente laboral cuando hablo, por ejemplo, con los propietarios de los helicópteros o las personas que les hacen el mantenimiento. Yo tengo que mostrar que sé, sin embargo, si llega un hombre... al hombre no le ponen ni la menor... puede decir cualquier tontería y no le ponen ninguna duda (Lorena, 44 años).

El segundo perfil, de los roles productivos hacia la centralidad de los reproductivos, es integrado por mujeres casadas o convivientes, que tienen hijos/as o que planean tenerlos en el corto plazo y que han migrado por motivos amorosos. La experiencia de estas mujeres se caracteriza por la reorientación y re-tradicionalización de sus roles, dejando atrás los productivos para ocuparse, de manera casi exclusiva, en las tareas del hogar, el cuidado y la crianza.

Yo tengo un súper buen currículum, humildemente lo digo, tengo un súper buen currículum, muchos años de experiencia, tengo 11 años de trabajo, tengo una carrera, tengo un nombre en México dentro de mi área, sin 
embargo, yo estoy dispuesta a perder eso, por ganar eso otro de familia (Matilde, 34 años).

A pesar de que han tenido dificultades para encontrar un empleo acorde a sus intereses y niveles de formación, no abandonan de manera tajante la idea de insertarse en el mercado laboral chileno, pues reflexionan que la exclusiva ocupación en actividades domésticas y de reproducción ha sido limitante en términos de inclusión social y económica "es la única razón por la que he buscado empleo, porque si he buscado... para poder integrarme un poco más a la sociedad, o sea, para conocer personas y simplemente salir de la casa" (Matilde, 34 años).

En este perfil, la separación entre las esferas de la producción y la reproducción se encuentra mediada por las ideas sobre el matrimonio y la maternidad, lo que podría dar luces acerca del papel que juegan estas condiciones en la mantención o trasformación de la estratificación y desigualdad de género. El hecho de mantener vínculos familiares en el nuevo contexto de migración es un elemento que no favorece las rupturas de dominación masculina, lo que se extiende a la determinación de la permanencia o la planificación de retorno. A pesar de esto, lo anterior no debe ser interpretado como circunstancia que imposibilita las oportunidades de re-interpretar, transformar o resistir dichas experiencias.

Lo único que me mantiene aquí es mi hija. Yo le decía que me quería ir a México y él me decía, bueno si tú te quieres ir a México yo no tengo nada que decirte, ándate, pero nuestra hija no se va. Y entonces como, no podía, no podía porque él tenía que firmar el permiso para salir y él decía que no, que no (Fernanda, 44 años).

"Sí, es algo que pienso mucho, porque yo cambie mi vida por él y él es la única razón que me mantiene aquí en Chile, no hubiera elegido Chile para vivir si no hubiera tenido esa razón" (Matilde, 34 años).

Dentro del tercer perfil, el problemático ensamble de los roles productivos y reproductivos, encontramos las experiencias de mujeres que han migrado por razones laborales o amorosas, se caracterizan por estar empleadas al momento de 
realizar las entrevistas y por compatibilizar esta actividad con el ejercicio de la maternidad. En estos casos, la maternidad se transforma en un punto de inflexión dentro de sus trayectorias migratorias que va direccionando sus proyectos personales y profesionales, además de abrir la posibilidad de investigar sobre nuevas habilidades y fortalezas.

Yo decía que no iba a tener hijos, no, la vida te cambia demasiado, me di cuenta de que soy más fuerte de lo que creí, emocionalmente, físicamente también. Y nada, me siento más capaz, si puedo con este niño, puedo con todo, así que emocionalmente me ha ido bien (Sofía, 28 años).

La responsabilidad de conciliar varios roles al mismo tiempo, productivos y reproductivos, genera tensiones entre la vida doméstica y la laboral, traduciéndose en escenarios de doble o triple jornada de trabajo, una sobrecarga laboral y circunstancias adversas que tienden a constreñir el desarrollo de las mujeres en alguna de las esferas, empujándolas a posibles elecciones entre lo uno o lo otro.

No era fácil, porque, por ejemplo, mi hija tenía jornada completa hasta las cinco, entonces yo en ese tiempo yo dije, tengo que hacer algo y ahí fue cuando empecé a trabajar (...) Entonces hacía eso, para devolverme con mi hija, cargarla cuando se quedaba dormida, horrible, yo me mataba, y llegar en la noche a tener que preparar la comida y todo para el día siguiente despertarme temprano parar llegar de nuevo a las nueve al jardín, no, entonces era mucho... (Fernanda, 44 años).

A pesar de esto, la igual importancia otorgada al trabajo asalariado y a las actividades de reproducción las ha llevado a buscar estrategias con el fin de compatibilizar ambos espacios, que van desde la posibilidad de acceder a modalidades de empleo flexibles hasta la articulación de redes feminizadas para el cuidado de los/as hijos/as. Para ellas, el empleo es considerado como sinónimo de independencia económica y como espacio que les permite la acumulación de capital económico individual y la satisfacción personal al sentirse "útiles".

A mí me gusta, me gusta sentirme útil. Yo siempre trabajé, desde que tenía 
15 años, en tonteritas, no sé, en una recepción, pero siempre trabajé. Y me gusta tener mi dinero. Para mí es independencia el trabajo, sí, independencia económica, no tener que estar esperando (Sofía, 28 años).

A pesar de que manifiestan el tránsito hacia relaciones de pareja más simétricas, negociando y dialogando sobre los gastos familiares y la distribución de tareas domésticas, las tareas de cuidado y crianza de los hijos e hijas sigue recayendo sobre sus hombros.

Igual le cuesta un poco. Como que él (pareja]) sabe que está mal, pero como que instintivamente me lo encarga a mí. Yo una vez le dije, que lo invitaron a carretear y dijo -Sí, yo voy-, y yo le dije -oye, pero asumes que tienes nana y ¿qué tal si no quiero cuidarlo? es sábado y yo quiero salir, o dormir o ver una película- y como que se enojó un poco, le dije -no asumas que mi tiempo es tuyo porque yo estoy con él (hijo) todo el día-. Te digo que sí le ha costado, él me ha admitido que su educación fue un poco machista, pero está luchando contra ello (Sofía, 28 años).

\section{“Estatus de mujer”, valoración y significados otorgados a la migración}

La decisión migratoria es un proceso complejo que se resiste a una reducción clasificatoria entre autónoma o dependiente, es más bien una negociación en la que juegan un papel importante las relaciones de poder inter-genéricas (Stang, 2006). Lo anterior permite dar cuenta de los procesos de negociación que se activan ante una eventual migración, sin embargo, esta afirmación deja de ser obvia al momento en que interpretamos los flujos migratorios de mujeres calificadas. Aquellas mujeres que migraron motivadas por razones educativas y laborales destacan a sus parejas y padres como figuras masculinas que conflictuaron la decisión de venir a Chile. Frente a este escenario, se activan procesos de negociación, imbricados en un "tire y afloje" entre lo que las parejas y las familias desean y los proyectos individuales de desarrollo personal.

Tenía un pololo como dicen acá, un novio, y fue como ya yo lo quería 
mucho y todo si hubo intención de contraer matrimonio, pero yo ya había postulado a esta beca, entonces para mí, mi prioridad era mi desarrollo profesional, entonces bueno desistí de la propuesta y me vine para acá (Carolina, 30 años).

Bueno y mi novio no quería que estudiara, yo le planteé incluso que no termináramos la relación, que siguiéramos y que el viniera para acá o que yo fuera y no, no, no. Entonces yo tuve que decidir por mí, o sea, lo amaba inmensamente, pero me quiero más a mi parece, es que me iba a perder la oportunidad de mi vida, de conocer todo esto si decía 'bueno, me quedo contigo’ (Ana, 29 años).

Desde este posicionamiento, es posible poner en relieve la capacidad de agencia de las mujeres por salir de los constreñimientos normativos provenientes del contexto familiar y cultural en origen, permitiendo cuestionar categorías históricamente naturalizadas que demarcan los límites entre lo femenino y lo masculino en formas de lo adecuado y lo inadecuado (Pantoja, 2010). Lo que emerge de las entrevistas, es que la decisión de migrar es impulsada, de una manera u otra, por desajustes e insatisfacciones con los contextos conservadores y tradicionales de origen. La migración es realzada como aventura que, entre otras cosas, permite cambiar de contextos socioculturales para la renegociación de identidades y la resistencia a la dependencia de modelos patriarcales donde se establecen roles tradicionales de manera normativa.

No, si estando allá, me sentía como no parte también, porque no era lo que yo quería, yo no quería terminar la carrera hacer dos o tres obritas, quedarme a hacer clases y quedarme en la casa encerrada. No es mi vida, no es mi estilo de vida, por eso yo en cierta manera, corrí a buscar otras cosas, salí por eso (Ana, 29 años).

La experiencia que constituye viajar $y$, con ella, el conocer nuevas culturas y 'modos de hacer' diferentes, permite no sólo romper el esquema, sino también el cuestionamiento, la re-estructuración y la re-definición de las propias pautas sociales y familiares heredadas desde el origen. Sin embargo, este romper el esquema no sólo 
se direcciona hacia la subversión de roles y estatus tradicionales en origen, sino que también pueden ser orientados a la re-tradicionalización.

Como plantea Suárez (2004), integrar el enfoque transnacional agrega complejidad al estudio de los roles y estatus de género, pero al mismo tiempo, permite contraponer, superponer o hibridizar las realidades a través de las prácticas de las propias mujeres. El transnacionalismo postula la existencia de nuevas esferas sociales transfronterizas, donde son los/as migrantes y sus interacciones quienes generan formas de socialización ya no exclusivas de una nación, sino que sobreponiendo dos o más sociedades a través de diversos tipos de conexión (Gissi, 2017; Glick Schiller y Fouron, 2001). Teniendo presente esta nueva realidad globalizada, constatamos que tanto roles como estatus de género ocurren en el contexto de una realidad transnacional que permite hacer un balance comparativo de su desempeño entre el aquí y el allá.

Lo que pasa es que, definir el machismo en estos tiempos yo creo que es difícil porque también hay cosas de idiosincrasia. Yo pienso que, en México, una situación como la mía, lo que yo he recibido el feedback que yo he recibido ahora que tomé la decisión de venirme aquí y trabajar en mi hogar es ay pero que afortunada, yo quisiera encontrarme un hombre así, que me saque de trabajar, que me saque, que me saque de trabajar, que me de todo y que además me lleve a viajar ay pero que buena suerte tuviste. Y aquí recibo el feedback al revés, '¡ay!, pero ¡cómo pudiste dejar todo por un hombre, y además no trabajas (Matilde, 34 años).

Me han preguntado si yo regresaría a vivir a Mérida y la verdad es que no, no regresaría a vivir allá, y cuando trato de imaginar mi vida allí, la verdad es que la imagino muy dueña de casa tal vez, me veo trabajando en la misma empresa donde trabajaba antes y ya estaría a punto de jubilarme, para hacer nada, para ser siempre la secretaria (Fernanda, 44 años).

La migración ha tendido a que las mujeres destaquen la sensación de haber ganado independencia, libertad, confianza en sí mismas y madurez. Al compararse con mujeres de su mismo entorno de origen y clase social, estas sensaciones son 
traducidas como 'ganancias' y 'avances' hacia un estatus menos subordinado a los dictámenes sociales. La independencia adquirida no se relaciona de manera exclusiva a lo económico, pues todas estaban empleadas antes de emigrar y tenían ingresos que era utilizados para asuntos propios, sino que, de manera principal, se asocia a la desvinculación parcial con el entorno familiar y social de México, el descubrimiento de nuevas habilidades y talentos, enfrentarse a sus propios límites y el conocimiento de nuevos y diferentes contextos sociales. De esta manera, el contexto migratorio es contemplado como espacio que propicia nuevas prácticas y realidades, sobre todo, en aquellas mujeres solteras y sin hijos que integran el perfil de la intensificación de los roles productivos, pues se sienten con más libertad y menos constreñidas por el entorno social de su país. Al respecto Ana dice: "mi vida, mi independencia la conocí acá, acá me conocí a mí, aprendí a hacer mi vida sola, me formé, trabajé acá, hice toda mi vida, desarrollé mi vida de adulta".

La independencia y la relajación frente a los roles de género se establecen como oportunidades para cuestionar el propio "estatus de mujer". Los roles dejan de ser entidades inmutables para dar paso a nuevas formas de pensar la maternidad, la crianza y la división genérica/sexual del trabajo.

(...) si no tengo el estatus social como mujer que se espera, bueno es problema mío, nadie me mantiene, yo me mantengo solita, yo hago lo que quiero, cuando quiero, como quiero, no digo que de vez en cuando pienso y digo 'ay sí, debe ser bonito', o sea de vez en cuando pienso, pero de eso a que yo sufra por no haber tenido una vida social como mujer, no, no, la verdad es que no (Lorena, 44 años).

La cita anterior revela las implicancias que tiene el cuestionamiento hacia la posición de género dentro de la estructura social y deja en evidencia que agitar y desestabilizar los tradicionales sentidos de la estructura no sólo implica disputar espacios que antes se encontraban inexplorados para las mujeres, también compromete el propio estar en el género. Dicho en otras palabras, "una mujer es mujer en la medida en que funciona como mujer en la estructura heterosexual dominante, y poner en tela de juicio la estructura posiblemente implique perder algo de nuestro sentido del lugar que ocupamos en el género" (Butler, 2007, p. 12). 
Así, las trayectorias migratorias de las mujeres calificadas mexicanas transitan a través de tensiones y desfases entre la estructura y la agencia, entre lo discursivo y lo performativo, poniendo límites a las posibilidades de acción al mismo tiempo que permite procesos de resistencia y desestabilización de las clásicas nociones de género.

\section{Conclusiones}

Emprender el camino hacia el análisis de las trayectorias migratorias y de género de mujeres mexicanas calificadas que migraron hacia Chile, es una tarea difícil, no sólo porque requiere de una mirada dinámica de la migración, que contemple la dirección que se da al proyecto migratorio, sino también, requiere por lo menos advertir, una serie de variables como la generación a la que pertenece la mujer, el ciclo de vida con el que ellas se identifican, el tiempo de permanencia en Chile, la situación conyugal y el tipo de convivencia en la unidad doméstica, las vinculaciones de los integrantes del núcleo doméstico con el trabajo reproductivo, la situación laboral, entre muchas otras.

A pesar de la centralidad otorgada a la educación, el trabajo y el amor en las motivaciones que originan la migración, comprender la transversalidad del dispositivo de género es tarea principal. La existencia de un sistema patriarcal en origen, que explica tanto las restricciones en la movilidad femenina, explícitamente visibles en los procesos de negociación familiar o de pareja, como los impulsos hacia la emancipación o la constante alusión a la independencia adquirida, podría tener fuertes influencias en el significado atribuido a la migración como posibilidad que permite re-configurar la propia identidad, que cobra aún más sentido en la lejanía y distancia con un entorno de origen restrictivo. A pesar de esto, no debe suponerse que la salida del sistema patriarcal en origen es hacia uno libre de éste, por el contrario, ambos están atravesados por la misma desigualdad. Ante esto, es importante mencionar que el dispositivo de género no se modifica o desequilibra exclusivamente a raíz de la migración. La migración por sí sola no actúa mejorando o empeorando las condiciones de vida de las mujeres de manera automática, sino que es preciso contemplar los contextos familiares, personales y sociales de los que 
pueden surgir diversas configuraciones en cuanto al posible impacto de la migración (Ariza, 2000).

Como vemos, los perfiles en torno a lo productivo/reproductivo muestran la diversidad de direcciones otorgadas a la migración y su relación con los roles de género, así como la complejidad que requiere el análisis de éstos. No se trata sólo de decir que la inserción de las mujeres en el mundo laboral o la esfera pública es sinónimo de emancipación, libertad y autonomía, sino que de problematizar la relación que existe entre la reproducción y la producción, entre lo privado y lo público y las constricciones y posibilidades que emergen de dicha vinculación. De esta manera, estos perfiles permiten dar cuenta de un continuo que va desde la elección por dedicarse de manera absoluta al cuidado de la familia hasta el enfoque exclusivo en el desempeño profesional y laboral. Independiente de las elecciones que cada una haya realizado, el problema radica en la dicotomía entre los espacios de la reproducción y la producción que obliga a las mujeres a tener que optar o bien, aceptar dobles y triples jornadas de trabajo. "El problema de fondo es que se debe decidir para así poder conciliar la esfera familiar con la pública, toda vez que el sistema vuelve dicotómica la vida social y cotidiana de las mujeres" (Gómez, 2013, p. 97).

En relación a la valoración de la migración, para todas las mujeres que participaron en esta investigación la migración permite el viraje y una reorganización de los roles hacia nuevas formas de ser mujer trabajadora/madre/pareja/hija. A pesar de las diferencias, emerge una idea común: ninguna sigue siendo la misma, pueden ocupar cargos de poder, estudiar posgrados, deciden si aceptan o no la maternidad y el matrimonio o cuándo y cómo quieren hacerlo.

La migración emerge como posibilidad de romper con las tradiciones, los esquemas y las insatisfacciones con los contextos conservadores y normativos que constriñen su estar y ser mujer en la sociedad, aunque siempre en un contexto transnacional donde dialogan el aquí y el allá. El ascenso hacia posiciones más emancipadas, independientes y autónomas permite problematizar la idea de que la migración impulsa el conocimiento hacia nuevos contextos socioculturales, permitiendo la renegociación de identidades y la resistencia a la dependencia de modelos patriarcales 
donde se establecen roles tradicionales de manera normativa.

A pesar de que las mujeres mexicanas calificadas que migraron reconocen encontrarse sujetas a contextos particulares de poder, ponen de manifiesto su propia capacidad de agencia al interior de los diferentes dispositivos de dominación. Las acciones y discursos que desestabilizan estas estructuras normativas han puesto en evidencia que la migración es un hecho social total que permite la construcción constante y no esencialista del género, otorgándole la posibilidad de ser transformado. El género ejerce su dominio, pero éste no es inmutable y no implica una condena hacia la repetición.

Hacemos hincapié en el vínculo dialéctico que existe entre la migración y las estructuras de género, poniendo en relieve la falta de consensos respecto al carácter emancipador o reproductor de la migración en las transformaciones de género (Suárez, 2004). Los hallazgos de esta investigación permiten afirmar que el dispositivo de género opera, aunque de manera más atenuada, sobre las mujeres calificadas mexicanas. La migración de mujeres calificadas permite redefinir las identidades, los roles y estatus de género, pero no necesariamente disminuye la desigualdad dentro de la estructura, aunque sí la desestabiliza. En la misma línea de los resultados propuestos por Stang (2006), una de las evidencias más claras es que, al momento de tomar la decisión de emigrar, aquellas que no tenían un vínculo formal de pareja y que no eran madres lo hacían con la finalidad de iniciar o continuar estudios de posgrado, desarrollarse profesionalmente, la posibilidad de encontrar un empleo o, simplemente, por la aventura que representaba la migración. Por el contrario, ninguna de las mujeres que al momento de emigrar estaban embarazadas, mantenían una relación de pareja formal o que migraron inspiradas por la idea del amor romántico, toman la decisión por razones estrictamente relacionadas a su formación. Así, tanto la maternidad como el matrimonio son condiciones que direccionan y marcan puntos de inflexión en la trayectoria de vida de las mujeres, siendo crucial su inclusión en el estudio de las migraciones.

Una segunda evidencia, es aquella que se expresa en la dificultad para congeniar las esferas de la producción y la reproducción. A pesar de que las mujeres que son madres y trabajan de forma asalariada procuran agenciar relaciones de pareja más 
simétricas y nuevas formas de llevar a cabo la maternidad, la responsabilidad de la crianza y el cuidado de los/as hijos/as recae siempre sobre sus hombros. Una tercera evidencia, es aquella que involucra los procesos de negociación: ninguna de las mujeres que migraron por razones amorosas/familiares destaca procesos de conflicto ante la decisión de migrar, ya sea porque la pareja estaba involucrada en el proyecto migratorio, o bien, porque la dirección de la migración, al menos en principio, estaba orientada al desempeño de roles que no conflictuaban con la estructura tradicional de los géneros (mujer esposa, mujer madre). Contrario a lo anterior, para las mujeres que migraron por razones educativas y laborales, los padres y/o parejas emergen como agentes que ponen en conflicto el desarrollo de proyectos personales asociados a la acción migratoria.

\section{Referencias}

Ariza, M. (2000). Ya no soy la que dejé atrás... mujeres migrantes en República Dominicana. Instituto de Investigaciones Sociales-UNAM. México: Editorial Plaza y Valdés.

Benería, L. (2006). Trabajo productivo/ reproductivo, pobreza y políticas de conciliación. Nómadas (Col), 24, 8-21.

Bermúdez, R. (2014). Trayectorias laborales de migrantes calificadas por razones de estudio. Estudios Demográficos y Urbanos, 29(2), 257-299.

Bodoque, Y. y Soronellas, M. (2010). Parejas en el espacio transnacional: Los proyectos de mujeres que emigran por motivos conyugales. Migraciones Internacionales, 5(3), 143-174.

Bourdieu, P. (2007). El sentido práctico. Buenos Aires: Siglo XXI editores.

Burgaleta, E. (2011). Género, identidad y consumo: las "nuevas maternidades" en España. Memoria para optar al grado de doctor en Métodos de la 
investigación y Teoría de la comunicación, Departamento de Sociología IV, Facultad de Ciencias políticas y Sociología, Universidad Complutense de Madrid.

Butler, J. (2007). El género en disputa: el feminismo y la subversión de la identidad. México: Paidós.

Butler, J. (1990). Performative Acts and Gender Constitution: An Essay in Phenomenology and Feminist Theory. Pp. 296-314. En S. E. Case (Ed.) Performing feminist: Feminist Critical Theory and Theatre. Baltimore: Johns Hopkins University Press.

Carrasco, C. (2001). La sostenibilidad de la vida humana ¿un asunto de mujeres? Barcelona: Icaria Editorial.

Cea, M. y Valles, M. (2010). Xenofobias y xenofilias en clave biográfica, Madrid: Siglo XXI.

Celiberti, L. y Serrana, M. (2009). Las relaciones de género en el trabajo productivo y reproductivo. Montevideo: Edición IPS de América Latina.

Cornejo, M.; Mendoza, F. y Rojas, R. (2008). La Investigación con Relatos de Vida: Pistas y Opciones del Diseño Metodológico. PSYKHE, 17(1), 29-39.

De Beauvoir, S. (1969). El segundo sexo. Buenos Aires: Siglo Veinte.

Departamento de Extranjería y Migración [DEM]. (2015). Registro de las visas y permanencias definitivas, otorgadas entre los años 2005 y 2014, a personas de nacionalidad mexicana a lo largo del país. Santiago: Ministerio del Interior y Seguridad Pública.

Duque, C. (2010). Judith Butler y la teoría de la performatividad de género. Revista La manzana de la discordia, 5(1), 27-34. 
Falquet, J. (2009). La règle du jeu. Repenser la co-formation des rapports sociaux de sexe, de classe et de "race » dans la mondialisation néolibérale, dans Elsa Dorlin (avec la collaboration d'Annie Bidet), Sexe, race, classe. Pour une épistémologie de la domination, PUF, collection Actuel Marx Confrontation. Traducción propia.

Federici, S. (2013). Revolución en punto cero. Trabajo doméstico, reproducción y luchas feministas. Madrid: Traficantes de sueños.

Folbre, N. (1994). ¿Who Pays for the Kids? Gender and the Structures of Constraint. Nueva York: Routledge.

Garcés, A. (2015). Migración peruana en Santiago. Prácticas, espacios y economías. Santiago: Ril.

García, B. y de Oliveira, O. (1998). Trabajo femenino y vida familiar en México. México: El Colegio de México.

García-Moreno, C. y Pujadas, J. (2011). No es fácil... y aquí tampoco. Trayectorias migratorias de mujeres cubanas en España. Revista de Dialectología y Tradiciones Populares, 66(2), 455-486. Madrid: Consejo Superior de Investigaciones Científicas (CSIC).

Gissi, N. (2017). Arraigo y desarraigo en los inmigrantes colombianos/as en Santiago de Chile. Incorporación social y transnacionalismo en el contexto de la globalización, En F. Aliaga (Ed.), Migraciones Internacionales. Alteridad y Procesos Sociopolíticos. Pp. 75-98. Bogotá: Universidad Santo Tomás (USTA).

Glick Schiller, N. y Fouron, G. (2001). Georges Woke Up Laughing: Long-Distance Nationalism and the Search for Home. Durham: Duke University Press Books. 
Gómez, C. (2013). Feminismo liberal y trabajo en el estado chileno: experiencias cotidianas de mujeres en un contexto laboral flexible. Tesis para optar al grado de Magíster en Estudios de Género y Cultura, Mención en Ciencias Sociales. Universidad de Chile.

Gorz, A. (1995). Capitalismo, Socialismo y Ecología. Madrid: HOAC.

Gregorio, C. (2012). Tensiones conceptuales en la relación entre género y migraciones. Reflexiones desde la etnografía y la crítica feminista. Papers. Revista de sociología, 97(3), 569-590.

Gregorio, C. (1998). Migración femenina. Su impacto en las relaciones de género. Madrid: Narcea, S.A de ediciones.

Lamas, M. (2003). La antropología feminista y la categoría de 'género', En Lamas, M. (Ed.), El género. La construcción cultural de la diferencia sexual. Pp. 97-125. México: Universidad Nacional Autónoma de México (UNAM).

Lozano, F. y Gandini, L. (2011). Migración calificada y desarrollo humano en América Latina y el Caribe. Revista Mexicana de Sociología, 4, $675-713$.

Martínez, J. (2011). (ed.) Migración internacional en América Latina y el Caribe Nuevas tendencias, nuevos enfoques. Santiago: Comisión Económica para América Latina y el Caribe (CEPAL).

Martínez, J. (2008). La migración femenina y la migración calificada. En J. Martínez, América Latina y el Caribe: migración internacional, derechos humanos y desarrollo, pp. 257-303. Santiago: Comisión Económica para América Latina y el Caribe (CEPAL).

Martínez, J. (2003). El mapa migratorio de América Latina y el Caribe, las mujeres 
y el género. Serie Población y Desarrollo 44. Santiago: Comisión Económica para América Latina y el Caribe (CEPAL).

Martínez, S. (2017). Desestabilizando las jerarquías. Roles y estatus en la migración de mujeres mexicanas calificadas en Santiago de Chile, Memoria para optar al título de antropóloga social, Departamento de Antropología, Santiago: Universidad de Chile.

Mauss, M. (1924). Ensayo sobre el don. Forma y función del intercambio en las sociedades arcaicas. Buenos Aires: Katz.

Mazzei, C. (2013). Producción y Reproducción: la mujer y la división socio-sexual del trabajo. Rumbos TS, 8, 128-142.

Ministerio de Desarrollo Social (2016). Sintesis de resultados encuesta CASEN 2015.

Mora, C. (2009). Estratificación Social y Migración Intrarregional: Algunas Caracterizaciones de la Experiencia Migratoria en Latinoamérica. Revista Universum, 1(24), 128-143.

Organización Internacional de Migraciones (OIM) (2014). La migración sur-sur: asociarse de manera estratégica en pos del desarrollo. Diálogo Internacional sobre la Migración $N^{\circ} 23$. Ginebra, Suiza.

Pacheco, E. y Blanco, M. (2008). Work and Family: An Exercise in Mixed Methodology, Forum: Qualitative social research Sozialfors, 9(1) art. 28. Recuperado de http://www.qualitative-research.net/index. php/fqs/article/ view/341/743

Pantoja, C. (2010). Relaciones de género y participación comunitaria de mujeres inmigrantes en Chile: el caso de las mujeres peruanas que pertenecen a colectivos de inmigrantes en la región metropolitana, Tesis de grado para optar al título de Magister en Psicología Comunitaria, Facultad de 
Ciencias Sociales, Universidad de Chile, Santiago.

Polloni, L. y Matus, C. (2011). Somos Migrantes. Experiencias de integración en la ciudad de Santiago. Santiago de Chile: Fundación Ideas.

Salt, J. (1984). High level manpower movements in northwest Europe and the role of careers. International Migration Review, 17(4), 633-636.

Sayad, A. (2010). La doble ausencia: De las ilusiones del emigrado, a los padecimientos del inmigrado. Barcelona: Anthropos.

Solimano, A. y Tokman, V. (2008). Migraciones internacionales en un contexto de crecimiento económico: el caso de Chile. En A. Solimano (Ed.), Migraciones internacionales en América Latina: Booms, crisis $y$ desarrollo. Pp. 185-244. Santiago: Fondo de Cultura Económica.

Stang, M. F. (2006). Saberes de otro género. Emigración calificada y relaciones intergenéricas en mujeres argentinas y chilenas. Buenos Aires: Consejo Latinoamericano de Ciencias Sociales (CLACSO).

Stefoni, C. (2001). Representaciones Culturales y Estereotipos de la Migración Peruana en Chile. Informe final del concurso culturas e identidades en América Latina y el Caribe. Programa Regional de Becas. Santiago: CLACSO.

Suárez, L. (2004). Transformaciones de género en el campo transnacional. El caso de mujeres inmigrantes en España. Revista de estudios de género La ventana, 20, 293-331.

Tapia, M. (2011). Género y Migración: Trayectorias investigativas en Iberoamérica. Revista Encrucijada Americana. 2, 115-147.

Texidó, E. y Gurrieri, J. (2012). Panorama migratorio de América del 
Sur 2012. Buenos Aires: Organización Internacional para las Migraciones (OIM), Oficina Regional para América del Sur.

Valerdi, M.Á. (2011). Trabajo de mujeres y cuidado de los hijos. Exploración en Irapuato, Celaya y León, Guanajuato. México: Plaza y Valdés.

Valerdi, M.Á. y Garabito, G. (2013). Impacto del trabajo productivo y reproductivo en el Bienestar de Guanajuato, Grupo de trabajo 11, Género, desigualdades y ciudadanía. Acta científica del XXIX Congreso de la Asociación Latinoamericana de Sociología (ALAS). Santiago. Recuperado de http://actacientifica.servicioit.cl/biblioteca/gt/GT11/ GT11_ValerdiAGarabitoG.pdf. 